\title{
LOS PROFESIONALES DE LA EDUCACIÓN CON FORMACIÓN DE POSGRADO QUE MÉXICO REQUIERE. INFORME, CONCLUSIONES Y RECOMENDACIONES DE LOS FOROS INTERNACIONALES DE FORMACIÓN DE INVESTIGADORES Y PROFESIONALES DE ALTO NIVEL EN EDUCACIÓN
}

M. de Ibarrola Nicolín; L.E., Sañudo Guerra; M.G., Moreno Bayardo y M.E. Barrera Bustillos [coords.].

Departamento de Investigaciones Educativas, Cinvestav IPN;

Facultad de Educación de la UADY; Red de Posgrados en Educación A. C.; Departamento de Estudios en Educación, U. de G.; REDMIE; ANEFEP. México, 2012.

El libro es resultado de la reflexión, autodiagnóstico, diálogo y debate sobre el tema relativo a la formación de profesionales de la educación a nivel de posgrado en México, realizado en el marco de dos reuniones internacionales secuenciadas. La primera en Mérida, Yucatán (2010) y la segunda, en Zapopan, Jalisco (2011). En sendas reuniones, un colectivo nacional e internacional de expertos interesados en el tema, debatieron sobre los posgrados en educación en México, con la finalidad de realizar propuestas para mejorar la calidad de los mismos. 
El texto se divide en varias partes: María de Ibarrola, coordinadora general y académica de ambas reuniones, introduce al lector en el tema, explicando en un primer momento, los antecedentes de investigaciones realizadas previamente en el país, que datan de los años sesenta en los que se publicó un primer análisis nacional sobre el «crecimiento desordenado» de las maestrías en educación. Para la década de los ochenta, se debatía sobre el alcance, nivel y la orientación de la formación que ofrecían los posgrados en educación. A mediados de los años noventa, se diagnosticó que los programas de posgrados - especialmente las maestrías en educación- podían clasificarse en tres rubros: el primero, representado por programas orientados a la formación de investigadores; el segundo, caracterizado por programas dedicados a la formación del personal docente y académico en general; el tercero, por programas que derivan en una forma especializada como la Psicopedagogía, la comunicación educativa, por ejemplo. Conforme a este diagnóstico se detectó que el esquema dominante era el escolarizado, caracterizado por la sobrecarga de cursos y/o unidades académicas.

En una primera parte, se presenta un contexto y se delimita la problemática del posgrado en educación en México. En este apartado se reflexiona en torno a la necesidad de un creciente número de investigadores y profesionales de alto nivel en educación en México. También se argumenta acerca de la necesidad de un creciente número de investigadores y profesionales de alto nivel en educación, sobre los programas de posgrado en educación existentes en el país, en torno a las condiciones en las que operan los programas de posgrado, la calidad y la evaluación de los mismos, y sobre los estudiantes y profesores. Asimismo, trata sobre los niveles y las modalidades de los programas de posgrados en educación; los mercados de trabajo posibles para los egresados; la formación integral que requieren los estudiantes de este nivel educativo; los universos de referencia y las diversas funciones profesionales.

En la segunda parte, se fundamenta conceptualmente y se marcan los referentes curriculares y modalidades de organización de los programas de posgrado. En este sentido, se delinean los ámbitos de proyección profesional en educación y alcance de los niveles de posgrado, se 
ubica el lugar que ocupa la formación en investigación en los diferentes posgrados (según el ámbito elegido de proyección profesional) y se enmarcan los universos en donde se desempeñan los profesionales de la educación con formación de posgrado, así como los contenidos de planes y programas, y las líneas de formación.

En la tercera parte del texto se aborda el proyecto académico y las modalidades de organización de los programas de posgrado, en donde se concluye que lo importante es la configuración congruente, pertinente y consistente, así como la estructuración correcta de los diferentes elementos curriculares que intervienen en los programas de posgrado. En ellos, es el aprendizaje lo que ha de considerarse como eje de la decisión sobre las modalidades elegidas, conforme al proyecto educativo deseado. De igual manera, las mediaciones (procesos y prácticas) empleadas en cada posgrado, han de articularse bajo el criterio de pertinencia al tipo y nivel de posgrado. Relevante resulta en esta parte del libro, los datos que se presentan sobre el ingreso, la permanencia y la eficiencia terminal de los estudiantes de posgrado; así como la vertida sobre el profesorado y el trabajo inter-institucional, coordinación académica y gestión del conocimiento.

Por último, las coordinadoras de esta publicación presentan un estado de las cosas, obtenidas éstas de los procesos de reflexión de las reuniones académicas en Yucatán y en Jalisco, y configuran una serie de alternativas posibles, a manera de conclusión.

Conforma una parte importante de este trabajo académico, la bibliografía, en la que se adjuntan las listas de ponencias y conferencias de las reuniones celebradas tanto en Mérida como en Zapopan, además de la lista de documentos de trabajo realizados para complementar la elaboración de las conclusiones y recomendaciones que se recogen en el texto. Asimismo, se anexan el programa de la primera reunión internacional de trabajo sobre la formación de investigadores y profesionales de alto nivel en educación, los objetivos, los participantes y la dinámica académica de la II Reunión Internacional sobre Formación de Investigadores y Profesionales de Alto Nivel en Educación, así como el programa 
académico y, por último, la lista de participantes de la reunión realizada en Mérida, en 2010, y de la efectuada en Zapopan, en 2011.

La información que ofrece este texto sobre la realidad de los posgrados en educación en México y los debates abiertos que se sugieren, son indispensables para todo aquel interesado en este tipo de temáticas, toda vez que el conocimiento colectivo aquí sistematizado, perfila al profesional de la educación que se quiere formar en los posgrados en educación en México, y aporta a la configuración una ruta de acciones que permitirían lograrlo si se cuenta con el apoyo de todos los actores sociales que inciden en la formación de profesionales de la educación en el posgrado.

Mónica del Carmen Meza Mejía 